\title{
O CINEMA E SUAS INTERFACES COM GÊNERO, SEXUALIDADE E EDUCAÇÃO FÍSICA
}

\author{
S. S. ANDRES ${ }^{1 *}$ e A. A. JAEGER ${ }^{2}$ \\ ${ }^{1}$ Instituto Federal do Rio Grande do Sul \\ ${ }^{2}$ Universidade Federal de Santa Maria \\ suelenandres@yahoo.com.br*
}

Artigo submetido em novembro/2015 e aceito em janeiro/2016

DOI: $10.15628 /$ holos.2015.3686

\section{RESUMO}

Nesta pesquisa objetivou-se conhecer e analisar as representações de gênero e sexualidade construídas por estudantes de um curso de formação profissional em Educação Física a partir dos filmes Tomboy (2011) e Assunto de Meninas (2001), que, respectivamente, abordam as duas temáticas. Após assistir cada película, realizou-se um grupo focal, contando com a presença de sete acadêmico/as do curso de Educação Física de uma universida de pública do Rio Grande do Sul. As discussões foram capturadas em um gravador digital e transcritas integralmente. As 56 páginas de material empírico foram submetidas a uma análise de conteúdo. Utilizar o enredo cinematográfico para criar as condições de possibilidade para a manifestação dos/as estudantes constituiu-se em uma produtiva estratégia para captar suas representações. A partir do filme Tomboy, emergiram noções acerca das relações de gênero ligadas a uma norma referente do que é entendido como meninomasculino e menina-feminina, indicando que o/as acadêmico/as afirmam e reafirmam noções normalizadas ao conectar linearmente sexo e gênero. Em Assunto de Meninas, a visibilidade da homossexualidade feminina produziu silêncios e desconfortos nas discussões. Contudo, a abordagem da obra suscitou a manifestação de representações centradas na heterossexualidade, sugerindo que outras sexualidades devem ser veladas e escondidas. Diante disso, conclui-se que as representações de gênero e sexualidade do/as estudantes de Educação Física aproximam-se de uma norma referente, na qual ser homem ou ser mulher deve estar alinhado com aquilo que se espera de um homemmasculino-heterossexual e uma mulher-femininaheterossexual.

PALAVRAS-CHAVE: Cinema, Sexualidade, Gênero, Educação Física.

\section{CINEMA AND ITS RELATIONS WITH GENDER, SEXUALITY AND PHYSICAL EDUCATION}

\begin{abstract}
This research aimed knowing and analyzing the gender and sexuality representations built by students in a professional formation course in Physical Education using the movies Tomboy (2011) and Lost and Delirious (2001) wich, respectively, approach the two subjects. After watching each film, we organized a focus group, that had the presence of seven academics from the Physical Education Course from a public univeristy of the state of Rio Grande do Sul. The discutions were captured by a digital recorder and fully transcribed. The 56 pages of empirical data were subjected to a content analysis. We noticed that using the movie plot to create the conditions of possibility for the manifestation of the students was a productive strategy to capture their representations. From Tomboy film emerged notions of gender relations
\end{abstract}

linked to a norm regarding what is understood as a malemasculine and female-feminine, indicating that the scholars affirm and reaffirm standardized notions when linearly connect sex and gender. In Lost and Delirious, the visibility of female homosexuality produced silence and discomfort in the discussions. However, the approach of the movie raised the manifestation of representations centered on heterosexuality, suggesting that other sexualities must be veiled and hidden. Therefore, it is concluded that the representations of gender and sexuality of the Physical Education students are similar to a standard reference, in which a man or a woman should be aligned with what is expected of a man-masculine heterosexual and a woman-feminine-heterosexual.

KEYWORDS: Cinema, Sexuality, Gender, Physical Education. 


\section{CONSIDERAÇÕES INICIAIS}

O cinema foi o entretenimento número um de milhões de pessoas até a década de 50 , quando os filmes inventavam modas, costumes e hábitos (DUARTE, 2002). No Brasil, em cidades como São Paulo e Rio de Janeiro, $80 \%$ da população frequentava salas de exibição pelo menos uma vez por semana (MENEGUELLO, 1996 apud LOURO, 2008b, p. 82). Hoje, com o avanço da internet, o acesso às produções cinematográficas em sites de compartilhamento gratuito ou pagos, como o Netflix, ficou muito mais fácil e econômico, colocando os filmes ao alcance de um público muito mais amplo.

Diante desse cenário, diferentes áreas do conhecimento vêm se utilizando do cinema como uma ferramenta pedagógica auxiliando no processo ensino-aprendizagem de uma série de temas, tanto na educação básica como na formação profissional, atingindo os mais variados níveis de educação. Belloni (2001) afirma que o cinema consiste em uma moderna tecnologia de ensinoaprendizagem e pode ser uma potente ferramenta, uma vez que na película as cenas e tramas recriam situações bem próximas da realidade. Tais enredos produzem pensamentos, emoções, conflitos e aflições capazes de deflagrar reflexões sobre as temáticas, visto que as discussões de determinadas cenas "pode ser utilizada como instrumento pedagógico significante para atingir objetivos educacionais" (DANTAS, MARTINS, MILITÃO, 2011, p. 69).

No campo das práticas corporais e esportivas, há mais de uma década reflexões e análises acerca do Cinema e suas interlocuções com o esporte têm sido publicadas (GOELLNER, 2005; MELO, 2009; DIAS, 2014; KNIJNIK e MELO, 2015). Ao mesmo tempo, algumas experiências realizadas na formação profissional em Educação Física que utilizam produções cinematográficas para produzir reflexões e conhecimentos têm sido registradas e publicadas (PINTO e PEREIRA, 2006).

$\mathrm{Na}$ esteira dessas ideias, buscamos entrelaçar o Cinema com a formação profissional em Educação Física, ancorando esse diálogo nos Estudos Culturais, os quais entendem as obras cinematográficas como artefatos culturais produtores e veiculadores de conhecimentos e saberes. Esses artefatos se constituem enquanto instâncias pedagógicas que ensinam aos sujeitos modos de ser e de se portar no mundo (SILVA e RIBEIRO, 2011), muitas vezes, produzindo vontades, possibilidades e ações.

Silva (2002), apoiado nos Estudos Culturais, aponta que a cultura, foco central de suas análises, é uma forma de pedagogia, assim como a pedagogia pode ser vista como uma forma de cultura. Nessa direção, entendemos que diferentes instâncias culturais e process os alheios ao saber sistematizado disseminado nas universidades e/ou escolas, também, são pedagógicos. Assim, concordamos com Silva (2002) quando afirma que as películas são, por si, pedagógicas. Para compreender melhor esse enunciado, nos apoiamos em Elizabeth Ellsworth (2001, p.11), que utiliza a noção de modos de endereçamento, cujo conceito é explanado a partir de uma pergunta inicial: "quem este filme pensa que você é?" E segue dizendo:

[...] para que um filme funcione para determinado público, para que ele chegue a fazer sentido para uma telespectadora, ou para que a faça torcer por um personagem, para que um filme a faça suspender sua descrença [na "realidade" do filme], chorar, gritar, sentir-se feliz ao final - a espectadora deve entrar em 
uma relação particular com a história e o sistema de imagem do filme (ELLSWORTH, 2001, p. 14).

Nesse sentido, a autora alerta que o modo de endereçamento está pautado na relação entre a intencionalidade do filme e a recepção que o/a telespectador/a faz dela. Assim, como exemplo, se um filme é endereçado a um público de garotos brancos, com idade de 12 anos e ricos, este deve estar em consonância com as supostas posições que esses garotos ocupam na vida real, para que diante dessa identificação eles "comprem" o que está sendo proposto no filme (ELLSWORTH, 2001).

$\mathrm{Na}$ esteira dessas recomendações, elegemos dois filmes que dialogam a partir de diferentes prismas com o contexto da formação profissional em Educação Física, possibilitando dife rentes posições de sujeito aos/às estudantes, uma vez que emergem diferentes noções sobre a generificação dos corpos, inclusive nas práticas corporais e esportivas (nesse caso o futebol), assim como podem perscrutar a partir de distintos prismas as relações tensas entre as manifestações das (homo) sexualidades no contexto escolar. Esses e outros temas atravessam as duas obras escolhidas e possibilitam que os/as futuros/as professores/as coloquem em questão determinadas verdades, vasculhando a formação profissional em Educação Física, assim como lançando luzes sobre os posicionamentos dos/as futuros/as docentes na educação escolarizada. Lembrando, mais uma vez Ellsworth (2001, p. 23), "a posição que um espectador ou uma espectadora "assume" em relação a um filme e dele extrai prazer, muda drasticamente, dependendo dos (conflitantes) modos de endereçamento que possam estar disponíveis".

Cesar, Gomes, Siqueira-Batista (2011) sublinham que a utilização de uma película é precedida de uma cuidadosa escolha; e mais: a abordagem pedagógica que orientará a discussão do tema em tela também deve ser minuciosamente planejada pelo/a professor/a, uma vez que precisa articular o assunto da obra aos conteúdos escolares, "de forma a manter a contextualização da atividade e sua consequente significação" ( p. 94). As escolhas criteriosas de filmes podem possibilitar à/ao professora/or que seja "capaz de mudar ou influenciar, até mesmo controlar, a resposta do espectador, produzindo um filme de uma forma particular. Ou você poderá ser capaz de ensinar os espectadores como resistir ou subverter quem um filme pensa que eles são ou quem um filme quer que eles sejam" (ELLSWORTH, 2001, p. 12). Partindo dessa premissa, escolhemos os filmes Tomboy (2011) e Assunto de meninas (2001) para discutir questões relativas a gênero e sexualidade em uma turma de estudantes do curso de Educação Física. Ambos os filmes foram exibidos em festivais alternativos, frequentemente voltados ao público que advoga noções sobre as relações de gênero e sexualidades pautadas na diversidade. Assim, se em determinadas cenas integrantes do grupo pesquisado não se identificavam com a intencionalidade do excerto, coube a nós, professoras e pesquisadoras, produzir modos de endereçamento em que integrantes do grupo, mesmo que por algum momento, e ainda que provisoriamente, tivessem pontos de apego para produzirem reflexões acerca da temática exposta. Dessas reflexões emergiam representações acerca das relações de gênero e sexualidades enunciadas pelos/as estudantes. Nesse sentido, Jaeger (2009, p.33) destaca que "a ideia de representação funciona como um sistema de significados produzidos na cultura através da linguagem e em meio às relações de poder".

Louro (2008b) explica que

\footnotetext{
"na contemporaneidade, o cinema, como tantas outras instâncias, pluraliza suas representações sobre a sexualidade e os gêneros. Por toda parte (e também nos
} 
filmes) proliferam possibilidades de sujeitos, de práticas, de arranjos e, como seria de se esperar, proliferam questões" (p. 94).

Tencionar as representações de gênero e sexualidade produzidas e reproduzidas nas aulas de Educação Física nos encaminha a refletir sobre diferentes maneiras de visualizar as formas de ser mulher/homem, como, também, pensar as diversas formas de vivenciar as sexualidades. Consideramos o cinema um poderoso artefato cultural para problematizar essas questões.

\subsection{O potencial pedagógico do cinema}

Há mais de um século o cinema passou a fazer parte das nossas vidas. As imagens em movimento, as cores e os sons surpreendem, encantam e contam diferentes histórias que nos fazem sonhar, compreender, desejar, afirmar, identificar, questionar, romper... Enfim, é um sem número de possibilidades que em síntese nos impelem a refletir sobre o cotidiano e, quem sabe, nos convoquem a projetar novos enredos para que outras histórias sejam vividas. Fabris (2008, p. 118) aponta que as histórias cinematográficas nos seduzem e "nos interpelam para que assumamos o nosso lugar na tela, para que nos identifiquemos com algumas posições e dispensemos outras". Assim, nos transportamos para outros lugares e tempos e, por alguns instantes, nos lançamos ao futuro ou retornamos ao passado ou vivemos mil vezes o presente nas suas mais incríveis e/ou banais possibilidades. Embarcar em uma viagem cinematográfica amplia as experiências da nossa própria vida. Nesse sentido, cinema e educação podem produzir conexões e diálogos, na medida em que o primeiro desafia a segunda, lançando alternativas, abrindo brechas, criando ruídos e apontando outras possibilidades. Em síntese, "o cinema pode conduzir a educação a novos lugares, a pensar o diferente" (DINIS, 2005, p. 69).

Não é de hoje que o potencial pedagógico do cinema tem sido utilizado nas diferentes esferas educacionais. Embora o número de estudos ainda seja pequeno (Duarte, 2002), o que se observa é um discreto aumento no interesse de pesquisadores acerca da aproximação entre cinema e educação. Walter (2015) afirma que a preocupação com o potencial pedagógico das obras cinematográficas no Brasil, foi inaugurado ainda nos anos 20 do século passado, quando professores e pensadores preocupados com a formação educacional apontavam a utilização de películas como ferramentas auxiliares ao trabalho docente. Entretanto, Dinis (2008) alerta que um filme não pode ser utilizado como uma repetição dos conteúdos abordados em aula, porque a linguagem cinematográfica escapa aos enquadramentos pedagógicos, ela é muito mais do que isso. Como diz Xavier (2008, p. 15) "a questão não é passar conteúdos, mas provocar a reflexão", ou seja, colocar sob suspeita aquilo que se tomava como um dado pronto, acabado, naturalizado. Como sublinha Fabris (2008, p. 120), "filmes são produções datadas e localizadas, produzidos na cultura, criando sentidos que a alimentam, ampliando, suprimindo e/ou transformando significados".

$\mathrm{Na}$ esteira dessas ideias, a potencialidade pedagógica que constitui cada enredo cinematográfico deve ser minuciosamente analisada pelo/a professor/a e orientar as suas escolhas, pois como nos lembra Rose (2001, p. 12) "traduzir o mundo em termos visuais [...] nunca é inocente. Estas imagens nunca são janelas transparentes para o mundo. Elas [...] apresentam o mundo de formas bem particulares". Ao assumir essa responsabilidade é importante que o/a docente faça as suas escolhas com muito cuidado, articulando o conteúdo que precisa ser abordado às temáticas representadas na tela (CEZAR, GOMES, SIQUEIRA-BATISTA, 2011), 
orientando-se a partir da seguinte questão: "a qual política educativa ele [filme] serve?" (WALTER, 2015 , p. 200). Afinal, as histórias contadas em tela são produzidas e produzem diferentes efeitos, os quais escapam ao que foi projetado e borram as fronteiras do contexto cultural em que foram pensadas, pois seus enredos produzem pensamentos, sentimentos, conflitos e questionamentos que acionam reflexões, posicionamentos e conhecimentos sobre os conteúdos pretendidos, encaminhando e ancorando os posicionamentos desses futuros professores, habituando-os a utilizar a relação teoria-prática na resolução de seus problemas. Nessa direção, além da escolha criteriosa do filme, os/as professores/s precisam eleger estratégias metodológicas adequadas à abordagem da temática, explorando diferentes modos de olhar para o conteúdo, "tornando a atividade rica, prazerosa e útil para a construção do conhecimento" (CEZAR, GOMES, SIQUEIRABATISTA, 2011, p. 98), permitindo que os/s estudantes incorporem conceitos e desenvolvam suas análises criticamente (Blasco, 2002). Muito mais do que um momento de entretenimento, a potencialidade pedagógica do cinema consiste nos modos como a obra interpela os sujeitos, seduzindo-os e convocando-os a produzirem as conexões desejadas, as significações alternativas e/ou criação de representações não imaginadas (ELLSWORTH, 2001). Os efeitos científicos, sociais e culturais dos diálogos entre sujeito e películas constituem o lugar central que o cinema pode ocupar em situações de ensino-aprendizagem, reafirmando o seu potencial pedagógico.

\section{METODOLOGIA}

Essa pesquisa utiliza uma abordagem qualitativa, o que permite a compreensão sobre os sentidos e significados que os acontecimentos têm para o grupo estudado (BOGDAN \& BICKLEN, 1994). A utilização de películas em investigações é um fenômeno recente no Brasil e, ainda não foi e nem está sendo, suficientemente estudado (DUARTE, 2002; FABRIS, 2008). Entretanto, os primeiros passos já foram dados e, paulatinamente, o cinema vem ocupando a centralidade de estudos em meio à construção de diferentes metodologias, oriundas de distintos campos do conhecimento (DINIS, 2005; PINTO, PEREIRA, 2006; DANTAS, MARTINS, MILITO, 2011; CÉZAR, GOMES, SIQUEIRA-BATISTA, 2011, LIMA NETO, NÓBREGA, 2014, GOMES, MORAES, HELAL, 2015). Na presente investigação, os filmes são entendidos como "textos culturais que ensinam, que nos ajudam a olhar e a conhecer a sociedade em que vivemos e contribuem para a produção de significados sociais" (FABRIS, 2008, p. 120). A reverberação e os efeitos desses significados foi o que nos interessou investigar. Em suma, privilegiamos as vozes dos sujeitos que assistiram "Tomboy" e "Assunto de Meninas", cujos enredos focalizaram as relações de gênero e as sexualidades, respectivamente. Sobre esses temas as/os estudantes se manifestaram e se posicionaram verbalizando conflitos, desconfianças, concordâncias, silenciamentos, etc. Entendemos a partir de Fabris $(2008$, p. 124) que essas representações acerca das películas são "produzidas e produtoras de práticas sociais e, assim, também de inclusões e exclusões sociais".

Para capturar os sentidos e significados na forma de representações produzidas a partir dos filmes pelos/as estudantes do curso de educação física, utilizamos a técnica de grupo focal, visto que estimula a interação entre as pessoas participantes da pesquisa. Essa técnica foi escolhida em função de os grupos focais facilitarem o desenvolvimento de estudos que procuram entender sentimentos, atitudes, preferências, necessidades e conflitos não claros ou pouco explicitados (DAMICO, 2004). Outra questão relevante na utilização de grupos focais é que isso oportuniza insights em vez de resultados (BARBOUR, 2009); o que, para a pesquisa em questão, foi de grande relevância, uma vez que o estudo, também, buscou proporcionar aos/às estudantes momentos de 
reflexão sobre os temas em discussão, oportunizando questionamentos, alterações, afirmações ou mesmo o abandono de algumas posições sustentadas por cada sujeito, acerca das relações de gênero e das noções de sexualidades.

Assim, elegemos como campo empírico um grupo de alunos/as participantes de uma Disciplina Complementar de Graduação (DCG), que abordava temas como corpo, gênero e sexualidade. Por essa ser uma disciplina não obrigatória, acreditamos que os acadêmicos/as nela matriculados/as estariam abertos/as a discutir as temáticas de gênero e sexualidade ou, no mínimo, importavam-se com elas. Embora a disciplina tenha começado com dezessete alunos/as matriculados/as, apenas oito frequentaram-na regularmente. Assim, o grupo focal da investigação foi formado por oito acadêmicos/as, sendo sete designadas do sexo feminino e um designado do sexo masculino, com idades entre 19 e 23 anos. Desses, sete pessoas pertenciam ao curso de Educação Física - Licenciatura e uma ao curso de Educação Física - Bacharelado. No primeiro dia de aula, juntamente com a apresentação da disciplina, foram feitos uma exposição da pesquisa e o convite para a participação nessa pesquisa, deixando claro que os filmes fariam parte da disciplina. Ressaltou-se que aquela/e acadêmica/o que não quisesse fazer parte da pesquisa teria suas discussões sobre os filmes e comentários desconsiderados nas análises, podendo continuar a cursar a disciplina sem nenhum prejuízo. Todos/as os/as alunos/as participantes da pesquisa assinaram o Termo de Consentimento Livre Esclarecido, autorizando a gravação das discussões e a utilização desse material na pesquisa, assim como garantimos o seu anonimato.

Conforme cronograma da disciplina, ogrupo focal se realizou em duas datas diferenciadas, de modo a contemplar a visualização e a discussão de cada filme separadamente. Destacamos que optamos, antes de iniciara sessão de exibição dos filmes, fazer uma leitura da ficha técnica da obra em questão. Entretanto, decidimos não ler as sinopses das películas para evitar a manifestação e a troca de impressões prévias sobre as obras. Após a visualização de cada filme, organizamos um círculo com todos/as participantes, e assim que ligávamos o gravador as discussões eram iniciadas. A pergunta: "Que pensam sobre o filme?" era a questão que servia como o fio condutor para outras questões, as quais deveriam pôr em cena a discussão dos temas relações de gênero e sexualidades.

Após os encontros e debates, as gravações foram transcritas para facilitar o processo de análise. Assim, as fontes de pesquisa resultaram em 56 páginas digitadas, as quais constituíram no material empírico dessa investigação. Para a interpretação e análise desse material optamos pela análise de conteúdo, descrita por Bardin (2011) como um conjunto de técnicas de análise da comunicação que visa, por procedimentos sistemáticos e objetivos de descrição do conteúdo das mensagens, obter indicadores quantitativos e qualitativos que permitam a inferência de conhecimentos relativos às condições de produção/recepção das mensagens. A autora propõe uma organização para análise dos achados, sendo dividida em pré-análise, exploração do material e tratamento dos resultados, que compreendem a codificação e a inferência desses resultados.

Ao organizar e analisar as fontes de pesquisa em função dessas orientações e dos objetivos da pesquisa, elaboramos duas categorias de análise, as quais são, respectivamente, oriundas de cada obra cinematográfica: gênero e sexualidades. 


\section{DISCUSSÕES E ANÁLISES}

\subsection{Discutindo gênero a partir do filme Tomboy}

O filme francês Tomboy ${ }^{1}$, escrito e dirigido por Céline Sciamma, conta a história de Laure, uma criança que se veste e age como menino. Devido à troca de emprego do pai, Laure e sua família têm que mudar de bairro. Nesse novo local, Laure se apresenta como Mickael, e Jenna, sua irmã, é a única que sabe que Laure se passa por Mickael na vizinhança, até que, após uma briga, seu segredo é descoberto por todos/as os/as seus/suas amigos/as.

Na primeira cena de Tomboy vemos a nuca de uma criança loira de cabelo curto com a cabeça para fora do teto solar do carro de seu pai. Essa criança tem uma aparência que remete à representação de um menino, pensando a partir de um padrão de corporalidade masculina referente, tanto pelo corte de cabelo quanto pela forma como se expressa e se veste, usando bermuda estilo surfista com camiseta de cor lisa e corte reto. Todos esses atributos normalizados como masculinos são reiterados quando a mãe pergunta se a cor do quarto - azul - está de acordo com o gosto da criança.

As primeiras cenas do filme nos convidam a olhar atentamente a criança que nos é apresentada, guiando-nos a enxergar a personagem principal como um menino, seja através de closes sobre ela, seja através de sua interação com as pessoas que fazem parte do seu cotidiano. Para as/o participantes dessa pesquisa, que não tiveram contato com a sinopse do filme e não sabiam o significado do termo Tomboy, nada parecia deslocado, continuavam ol hando o filme, esperando os próximos acontecimentos. Isso muda quando a mãe de Mickael-nome que a criança utiliza ao se apresentar aos amigos/as da vizinhança - o chama para que ele retorne a sua casa, chamando-o de Laure. Esse desencontro produz questionamentos e dúvidas sobre a criança. Afinal, será Mickael uma menina? Imediatamente, a próxima cena elucida a questão: Mickael está tomando banho em uma banheira com sua irmã Jeanne. Ao sair da banheira, em um rápido movimento de câmera, nota-se a genitália feminina de Laure/Mickael.

Esse é o enredo que suscitou as discussões com estudantes e a partir do qual emergiram representações acerca das relações de gênero e dos atributos, comportamentos e da aparência que constituem um mosaico de informações que inscrevem identificações nos corpos dos sujeitos.

A forma como somos interpelados/as pelo que nos qualifica enquanto meninas/mulheres e meninos/homens são construídos desde a gestação e definem, amiúde, o nome, a cor do quarto, das roupas, os brinquedos e até mesmo a futura profissão dessa criança. "Estamos nos constituindo como sujeitos, com múltiplas identidades (de gênero, de etnia, religiosas, sexuais, etc.), embora, muitas vezes esses aspectos sejamignorados, sendo vistos apenas sob a perspectiva essencialista", alerta Souza (1995, s/p). Nessa direção, notamos que as manifestações do/as acadêmico/as sobre as representações de gênero convergem para a necessidade de inscrever no corpo de Mickel/Laure a verdade indubitável do seu sexo (JAEGER e GOELLNER, 2011), ou seja, se é menino ou menina. Essa representação é sustentada em boa medida nas atividades realizadas pela criança, nas suas cores prediletas, nas roupas que veste e nos sentimentos que deixa aflorar.

\footnotetext{
${ }^{1} \mathrm{~A}$ tradução literal é menina-moleque. A película ganhou alguns prêmios, entre eles Melhor filme no 19을 Festival MixBrasil da DiversidadeSexual e no LGBT do Festival de Berlim, prêmio do público no Frameline Gay \& Lesbian Film Festival, de San Francisco/EUA, melhor Ionga do Philadelphia QFestival de Cinema Gay e Lésbi co e, novamente, o prêmio máximo no Torino Lesbian and Gay Film Festival, todos em 2011.
} 
A película também deixa vazar em suas cenas essas representações quando Laure é confundida com um menino pelo fato de vestir bermudas largas até o joelho estilo surfista, camisetas largas de cores lisas e corte reto, que culturalmente remetem e representam o modo referente da vestimenta masculina, assim como o seu corte de cabelo curto reafirmava essa noção.

Nessa situação podemos entender a partir da explicação de Meyer (2000, p. 152-153) quando afirma que "as representações hegemônicas de gênero [...] fixam padrões nos quais se institui o que é ser homem e mulher, como se educam meninos e meninas e, por extensão, o que podem/devem fazer da/na vida". Tais representações podem serfacilmente identificadas na s falas do/as estudantes proferidas nas discussões do grupo focal.

\footnotetext{
"Ahhh... se a gente vê a irmã, ela usava vestido na maioria das vezes, ele não, sempre de bermudão, camisetão e tênis." (Sujeito 4)

"É... é roupa de menino né?!?! E o cabelo é um corte que os meninos usam, estilo Joãozinho." (Sujeito 3)

“É, não é um corte [de cabelo] que meninas usam." (Sujeito 1)

"Isso, e a forma como ele se portava e, junto com as roupas e o cabelo, fica muito visível um menino." (Sujeito 7)
}

Pois se o que define o gênero são as formas de vivenciar as feminilidades e as masculinidades, os mesmos padrões são postos em funcionamento para designar o pronome que foi utilizado pelo/as acadêmico/as para fazerem referência à Laure. Vejamos alguns fragmentos nos quais a aparência tomada a partir de uma representação fixa daquilo que é designado como mais adequado para os meninos, juntamente com a forma como Laure se constitui, é atribuído como elemento identificador de seu sexo, sendo marcante ao ponto de todas/o as/o estudantes se referirem a ela como "ele". Como vemos nas falas:

“[...] pela maneira com que ele fez, [...] envolveu a irmã dele pra que ela ajudasse na mentira e ao mesmo tempo os pais dele que não entenderam o lado dele." (Sujeito 4)

“Na verdade a mãe dele não entendeu." (Sujeito 2)

"[...] é...dava para perceber que o pai tinha ele como mais menino do que como menina." (Sujeito 7)

A não linearidade de sexo-gênero demonstrada na personagem do filme acaba causando um emaranhado de questionamentos sobre o que é designado/permitido para uma menina ou para um menino. Pois, se por um lado, a aparência de Laure a aproxima de um jeito de ser e se vestir que remete à representação da masculinidade padrão, desnaturalizando seu sexo biológico, o mesmo é contrastado com algumas representações ao que é tomado como feminino referente. Isso pode ser percebido na fala a seguir:

"[...] por mais que ele fosse forte, jogasse futebol bem ele tinha os momentos mais carentes, aquela parte que ele estava abraçado com o pai dele e o pai dele ficava com ele no colo é um momento de carência que é mais da filha com o pai, no caso dificilmente um filho na idade dele vai se sentar." (Sujeito 4) 
Novamente evidencia-se a polarização menina/menino e masculino/feminino e o que é esperado em termos de comportamento afetivo de uma e de outro. Todavia, como aponta Louro (1997, p. 31, 32), "aprendemos a pensar e a nos pensar dentro dessa lógica". É dentro dessa lógica que podemos perceber que a representação de gênero para o/as pesquisado/as não está propriamente no sexo ou nas características sexuais, mas ao que associamos aos sexos, à forma como são representados os comportamentos, valores e habilidades.

Nesse processo, diferentes instâncias colaboram para a constituição das identidades de meninos e meninas, território no qual a família ocupa posição central, visto ser ela a primeira instância de socialização da criança, lugar em que aprende limites e possibilidades. Em relação ao gênero, desde cedo as crianças são ensinadas que a menina deve educar os seus gestos, gostos, tom de voz, vestuário e sentimentos alinhados à representação de uma feminilidade normalizada. Enquanto os meninos aprendem, por seu turno, o que devem fazer, desejar e manifestar para incorporar certo padrão de masculinidade. Tanto as noções de feminilidade quanto as de masculinidade produzem e são produzidas em função da cultura de determinado tempo e lugar. Assim, desde cedo as crianças são educadas para desejar e incorporar aquilo que o seu contexto cultural produz como adequado ao sujeito homem e ao sujeito mulher. Essas representações de masculinidade e feminilidade são de tal modo afirmadas e reafirmadas no cotidiano que possibilitam poucos borramentos entre os sexos.

Assim,

Se diferentes instituições e práticas sociais são constituídas pelos gêneros (e também os constituem), isso significa que essas instituições e práticas não somente "fabricam" os sujeitos como também são, elas próprias, produzidas (ou engendradas) por representações de gênero [...] (LOURO, 1997, p. 88).

Nesse sentido, a constituição do que é uma família também não escapa das representações que a cultura produz sobre ela. No filme em tela, deparamo-nos com um modelo de família tradicional, com pai, mãe, duas filhas e um filho a caminho. Os papéis e funções estão bem demarcados, sendo o pai o responsável pelo sustento da família, enquanto a mãe dedica-se aos cuidados das/os filhas/os, produzindo e reproduzindo o que socialmente e culturalmente ainda se espera de uma mulher e de um homem no contexto familiar tradicional. Tomando como foco de análise a constituição familiar, apontamos que as/o acadêmicas/o posicionam a mãe como a responsável pelo modo que Laure se veste. Como percebemos nos excertos:

\footnotetext{
“Mas é estranho porque até a mãe, às vezes, ...quando eles se mudaram para a casa nova, ela disse assim:-Ai tu gostou do teu quarto azul? Né! Então é estranho, as vezes parecia que até ela estava ahmm, no inicio do filme a gente não consegue identificar que ela é uma menina né?! Se é... a mãe mesmo, e o quarto dele é totalmente diferente do quarto da irmã né ?!" (Sujeito 5)

"[...] a gente sabe que a gente sendo criança, então quem é que compra roupas, quem é?? A mãe! (todas falam ao mesmo tempo) Não é nem o pai. É a mãe." (Sujeito 2 )
}

Se a mãe é incumbida de cuidar/escolher as roupas das filhas, entende-se que se a filha se veste como menino, a mãe permitiu que isso acontecesse. Carvalho (2004) comenta que, muitas vezes, a educação das crianças, tanto em casa como na escola, fica sob responsabilidade 
exclusivamente da mãe. Ao pai restam as decisões mais burocráticas, normalmente atreladas ao es paço público, enquanto a mãe fica mais restrita ao espaço privado. Nesse contexto, o enredo do filme e as manifestações das/o estudantes convergem. Porém, algumas atitudes do pai também são apontadas como constitutivas para a forma como Laure se comporta, como vemos nos enunciados abaixo:

"Na parte que ele ensina a dirigir, na parte que ele dá cerveja, jogando." (Sujeito 4)

“[...] jogando também é nas partes que dá para ver que é uma relação pai e filho e não pai e filha." (Sujeito 6)

"Hahh, uma relação onde... onde o pai fosse carinhoso, não que ele não fosse, mas acho que os pais não fazem questão de que uma menina beba [álcool], nehh??" (Sujeito 5)

"É. E isso de oferecer cerveja para experimentar, é coisa que pai faz com um filho homem, ensinar a dirigir, jogar... o pai sempre vai ter uma relação de carinho, proteção com uma filha mulher." (Sujeito 4)

"Também acho, a mãe vai ensinar a menina coisas da casa, limpar, lavar... até porque a menina normalmente fica em casa com a mãe e o filho sai com o pai, fazer coisas de homem...jogar, beber... acho que é muito forte essa divisão." (Sujeito 1)

Novamente podemos visualizar a reiteração das diferenças entre homem e mulher, e quando pensado numa relação de pai/mãe e filho/filha, o que apresentam é uma estrutura binária, na qual o pai é responsável por fazer de um filho um homem e a mãe ensina a filha a ser mulher, atendendo, assim, às expectativas sociais do que é esperado de um homem e de uma mulher, reiterando também as divisões sociais e polarizadas dos espaços privado/público.

As representações apresentadas pelas/o pesquisadas/o em relação ao gênero estão ligadas a uma estrutura binária, na qual existem atribuições referentes ao que se espera de meninos/homens e das meninas/mulheres. Todavia, reconhecem em Laure uma masculinidade em um corpo designado do sexo feminino, rompendo sem perceber, em certa medida, com a linearidade sexo-gênero. As discussões acionadas pelo filme oportunizaram diferentes reflexões aos/às acadêmicos, abalaram algumas certezas e possibilitaram o questionamento acerca das normas de gênero. Sobretudo, muitas cenas abriram brechas para que outros modos de pensar enunciassem novas representações, suscitando ampliar e aprofundar os estudos sobre a temática na formação profissional em Educação Física.

\subsection{Assunto de Meninas: quando a homossexualidade entra em cena}

O filme canadense, com roteiro de Susan Swan, Judith Thompson e direção de Léa Pool, "Lost and delirius/Assuntos de Meninas", tem em seu elenco atrizes de renome como: Misha Barton, Piper Perabo e Jessica Paré. Participou da seleção do festival de Sundance de 2001 e levou alguns outros prêmios menos importantes. O filme é ambientado em um internato feminino e conta a história de duas garotas que vivenciam uma paixão mútua. $O$ enredo é contado a partir de uma terceira pessoa, Mary, que é enviada ao internato após a morte da sua mãe e o novo 
casamento do seu pai. Uma menina tímida, mas que logo faz amizade com Tory e Paulie, duas garotas com as quais ela irá dividir quarto. Mary logo percebe o que motivou a direção do internato a encaminhá-la para dividir o quarto com as duas colegas, pois descobre que elas possuem uma relação que vai além de uma simples amizade.

Mesmo não compreendendo claramente o que acontece entre as garotas, Mary passa a ser confidente dessa relação que logo entra em crise. Depois de uma noite de amor, as meninas ainda estão na cama na manhã seguinte e são surpreendidas pela irmã mais nova de Tory, cujo flagra acaba culminando no rompimento do relacionamento entre as garotas. Após o ocorrido, enquanto Paulie procura de todas as formas retomar a relação, Tory acaba se envolvendo com um garoto para acabar com qualquer boato sobre as duas. Em meio a esses acontecimentos, a colega de quarto e duas professoras tentam acalmar a situação, mas não impedem o fim trágico na história de Tory e Paulie.

O filme foi o marco inicial para discutir sexualidade com as/o estudantes, procurando partir da perspectiva não heterossexual. Dessa forma, partimos de dois eixos centrais para discutir sexualidade, no primeiro, discutimos o impacto do filme e suas representações de sexualidade. No segundo eixo, objetivamos problematizar o filme e discutir a representação da homossexualidade a partir do posicionamento das/o acadêmicas/o no lugar do outro.

Discutir sexualidade entendendo-a como os modos que cada sujeito vivencia seus desejos e prazeres (WEEKS, 1999), não é tarefa fácil. Ainda mais, quando a representação da sexualidade em tela focaliza sujeitos que vivenciam sua(s) sexualidade(s) fora da referência heterossexual. Ao centralizar a discussão na relação afetiva-sexual entre duas garotas, retratada na película de forma clara e explícita, pareceu, em um primeiro momento, ser uma boa escolha, segundo os modos de endereçamento (Ellsworth, 2001). O filme abordava as relações afetivas-sexuais de duas garotas em um contexto escolar. Pensando nessa abordagem e considerando que o grupo focal era constituído, quase em sua totalidade, de mulheres, que estão em processo de formação para atuarem como professoras em escolas, e que, a qualquer momento no exercício de sua profissão poderão se deparar com situações semelhantes. Entretanto, ao analisar o material produzido no grupo focal, encontramos o registro de longos e repetitivos silêncios, o que nos fez rememorar os momentos de expectativa e tensão quando lançávamos as perguntas ao grupo e ninguém se manifestava: Então, estudantes, o que acharam do filme? $E$ aí meninas? $O$ que destacariam do filme? Como vocês veem a relação entre as duas? E qual seria a reação de vocês?

Como resposta às perguntas, obtivemos apenas silêncios repetidamente. Assim, como efeito do silêncio, repercutem inúmeras representações, experiências e questionamentos. Entendemos que a sua manifestação, também, pode ser fruto de uma sociedade reguladora, pois "o tema sexualidade revela-se polêmico, envolvendo tabus, medos, questões religiosas, morais e éticas [...]" (FERREIRA e LUZ, 2009, p. 33). Emudecer-se diante da temática expõem dificuldades múltiplas ao abordar o tema. Nesse grupo em específico, acreditamos ser necessário considerar duas questões ao buscar entender tal relutância.

A primeira é a reflexão acerca de seus conhecimentos sobre sexualidade, obtidas em es paços familiares, de educação formal e, também, por meio de diferentes artefatos culturais. No grupo de acadêmicos/as, com exceção de um/a, todos/as os/as outros/as saíram do ensino médio para a universidade e, em alguns casos, em cursinhos pré-vestibulares. A sexualidade, tanto no ensino médio como nos cursos preparatórios para o vestibular, é abordada em grande parte com 
base na biologia, versando sobre questões reprodutivas e de prevenção a doenças sexualmente transmissíveis (DST's). Essa forma reducionista de ver a sexualidade associada apenas ao ato sexual faz com que desconsideremos a relação com o corpo, o prazer e o desejo (FERREIRA e LUZ, 2009) negando ou "desconsiderando as implicações subjetivas, relacionais e sociais da vivência da sexualidade" (LIONÇO e DINIZ, 2009, p. 53).

A segunda consideração refere-se ao perfil do grupo, que era formado por sete pessoas, sendo que, seis se declararam do sexo feminino e um do sexo masculino. Por se tratar de um grupo eminentemente formado por mulheres e o filme tratar da homossexualidade feminina, é preciso considerar que em torno da mulher é articulado um forte controle da sua sexualidade, sendo ela educada para ser recatada e conter os seus desejos sexuais. Por outro lado, a sexualidade masculina é fortemente estimulada como um componente determinante da construção da masculinidade referente. Diante desse contexto, a única semelhança nesses encaminhamentos sociais é que ambos são direcionados à heterossexualidade. Visto assim, o silêncio também pode ser fruto de uma rígida educação, na qual diferentes instâncias nos dizem, "sobre o que falare sobre o que silenciar" e, também, "quem pode falar e quem deve ser silenciado" (LOURO, 2007, p. 33).

Diante do silêncio atemorizante, alteramos o enfoque das questões. A mudança na abordagem produziu efeitos e o recorte de uma cena nos possibilitou ouvir as/o acadêmicas/o. Assim, foi proposto esmiuçar a cena em que o relacionamento afetivo-sexual entre as duas personagens do filme deixa de ser um segredo e, a partir desse enredo, as/o acadêmicas/o se manifestaram sobre a situação. Ao que destacaram:

"Eu não sei se para vocês ahmm, mas naquele momento que a irmã dela pergunta: _Tá, mas tu ? que ela já interrompe e diz:_Não, eu gosto de meninos! Quem que garante que a irmã dela não fosse dizer:_Olha, eu vou estar do teu lado." (Sujeito 4)

"Ela nem esperou para saber a reação da irmã ela já foi né, se armando de argumentos para que ela nem pensasse naquilo." (Sujeito 7)

“É, mas, a irmã já disse logo que entrou na porta que nem pensasse." (Sujeito 5)

“Sim, mas é uma defesa ela se defendeu para as amigas e para a irmã." (Sujeito 2)

"Quem pensa num segundo momento se ela não ia aceitar, se fosse só ela e a irmã dela." (Sujeito 1)

"É porque ali ela estava na frente das amigas, se a sociedade tem essa visão, então na frente das amigas ela talvez quisesse mostrar que ela também tinha essa visão, mas quando ela estivesse em um momento só ela e a irmã, talvez ela até apoiaria a irmã e tal, só que a irmã nem pensou nisso."(Sujeito 4)

Ter exposta a sexualidade quando ela foge aos padrões heteronormativos pode estabelecer situações desconfortáveis entre o/as envolvido/as. A cena apontada pelas/o sujeitos acaba demonstrando o que Berenice Bento (2010) nomeia de heteroterrorismo, que nada mais é que inúmeros discursos, atitudes, incentivos e inibições em favor da heterossexualidade tomada como única e possível forma de vivenciar a sexualidade. Isso acaba refletindo no impulso de Tory, que, 
rapidamente, manifesta-se gostarde meninos, buscando assimafastar sus peitas sobre sua possível homossexualidade.

Outro ponto a destacar é que "embora para a instituição heteronormativa da sequência sexo-gênero-sexualidade concorram diversos es paços sociais e institucionais, parece ser na escola e na família onde se verificam seus momentos cruciais" (JUNQUEIRA, 2012, p.7). Focando na instituição família, questionamos sobre como reagiriam no lugar da irmã mais nova ao flagrar o relacionamento afetivo-sexual da irmã mais velha. As/o acadêmicas/o dizem:

"Acho que em um primeiro momentoeu agiria igual a ela, mas naquele estado de choque." (Sujeito 5)

"Mas eu também agiria assim, mesmo sendo, porque quando eu soube do meu irmão eu não gostei muito da ideia. Mas é bem naquilo, não pelo fato de ser, mas por tudo aquilo de problemas sociais que a pessoa vai passar, de preconceito, da aceitação." (Sujeito 2)

"Eu acho que também reagiria da mesma forma que a gente já vem muito embutido, muitas coisas, que a sociedade impõe, então em um primeiro momento eu acho que tu sempre ficaria meio chocado." (Sujeito 7)

"Eu não sei se eu agiria da mesma forma, porque uma prima minha é lésbica e eu conheço a namorada dela, vi elas muitas vezesjuntas e para mim nem na primeira vez eu fiquei chocada." (Sujeito 4)

"Eu acho que tu pensa primeiro assim:_Ai, o que meus pais vão pensar!" (sujeito 3)

Ao pensar a sexualidade não podemos "separá-la dos aspectos culturais, político, social e econômico" (FERREIRA e LUZ, 2009, p. 35). E os enunciados acima não o fazem, todavia, enxerga se a homossexualidade de alguém próximo como algo não esperado, algo que burla e foge do que Ihe foi ensinado. Mostrando como a heteronormatividade tem sido eficiente, pois enquanto ela é tida como "inata e natural, é alvo da mais meticulosa, continuada e intensa vigilância, bem como do mais diligente investimento" (LOURO, 2007, p. 17).

Essa vigilância/investimento é percebida no filme quando Mary passa a dividir o quarto com Tory e Paulie, essa foi a forma que a escola articulou para por fim ao relacionamento das duas garotas. Essa foi outra cena que veio à tona para discutir a escola como instância que, também, produz a reproduz representações de sexualidades. Nesse caso, o cinema possibilita às/ao acadêmicas/oincorporar noções e conceitos que serão requisitados na construção de suas análises e posicionamentos (BLASCO, 2002). Nessa direção, ao serem questionadas/o sobre como agiriam se tivessem um casal homossexual na escola, as/o acadêmicas/o disseram:

"Depende que proporção vai as coisas né, depende muito da situação, da escola,...depende de várias coisas." (Sujeito 3)

"Acho que a escola vai se tornar um auxiliador, entre esse casal e os outros e entre essa casa e a família, porque normalmente, os pais têm problemas com os filhos e eles trazem para a escola, para a escola também ajudar a resolver. Nesse caso como vazou na escola, a escola vai tomar frente junto aos pais e tentar fazer eles entenderem isso. Eu no meu caso como professora, é o que eu iria fazer, é tentar 
conversar com os pais, explicar que aquilotambém está certo que não é o errado, e que eles precisam ajudar os filhos, eles precisamficar do lado dos fil hos que eles vão precisar e muito...." (Sujeito 2)

“É, tem que ter apoio da família e perante os outros colegas o resto da escola também, eu acho que isso seria um trabalho dos professores da escola, de tentar ajudar." (Sujeito 4)

Ao introduzir a escola no debate, percebe-se que em duas falas o/a professor/a seria um/a mediador/a em relação à família e destacando o lugar central do apoio familiar nesse momento. Por meio dessas afirmações, podemos recorrer às falas anteriores, na qual a suspeita de ter um irmã/ão homossexual gera toda uma preocupação com o que os/as outros irão dizer. Mas quando a questão sai do círculo familiar o que se vê é um apoio, "eles precisam ficar do lado dos filhos", seguido de um "eles vão precisar e muito". Tais posicionamentos afirmam e reafirmam representações ancoradas na noção de que pessoas que se afastam da heterossexualidade vão sofrer algum preconceito. O efeito disso recai na ideia de que se a pessoa homossexual pertencer ao seu círculo íntimo, você também será afetado ou alvo de preconceitos e discriminações. Por outro lado, parece que as sexualidades vividas fora da norma heterossexual não causariam tanto incomodo aos sujeitos investigados quando vividas por pessoas fora do seu núcleo familiar. Nesse sentido, importa destacar que a família é uma das instâncias que produz e reproduz preconceitos e discriminações, os quais são muitas vezes reafirmados, primeiramente, na escola (JUNQUEIRA, 2009), e, depois, na formação profissional. Assim, tanto na família como na escola e mesmo na formação profissional é a heteross exualidade que ocupa a posição central, as demais são tomadas como problemáticas e, portanto, indesejáveis.

Diante desse cenário complexo, a Educação Física tem sido apontada como uma potente disciplina escolar para tematizar a sexualidade transversalmente aos seus conteúdos (PRADO e RIBEIRO, 2010; LOURO, 2008a; ALTMANN, 2001), em função da centralidade dos corpos, gêneros e sexualidades em suas aulas, de suas metodologias, condutas e relações entre professores/as e alunos/as. Todavia, Altmann (2013) alerta que, especificamente, a sexualidade emerge mais nos discursos produzidos na escola do que naqueles que constituem os cursos de formação profissional. Assim, se pretendemos que esses futuros/as professores/as sintam-se habilitados/as a desenvolverem as tarefas educativas que a dinamicidade do cotidiano lhes impõem, precisamos oportunizar uma formação profissional que contemple essas problemáticas. É nesse cenário que o cinema desponta "[...] não só como arte, mas como linguagem mobilizadora e desestabilizadora das nossas certezas" (XAVIER, 2008, p. 14); e, mais, quando algumas vivências culturais dialogam com "uma certa maneira de ver filmes, acabam interagindo na produção de saberes, identidades, crenças e visões de mundo de um modo contingente de atores sociais" (DUARTE, 2006, p. 19).

Assistir "Assuntos de meninas" e debater com as/o acadêmicas/o a temática da homossexualidade, utilizando o cinema como uma ferramenta de ensino-aprendizagem, fissurando certezas e trazendo à tona preconceitos e discriminações, constituiu-se em um delicado desafio. Ao mesmo tempo, apontou que a formação profissional em Educação Física tem secundarizado, senão relegado às zonas de sombra, essa discussão. Tal posicionamento dificulta ou inviabiliza que a área assuma o compromisso para o qual está sendo apontada por diferentes estudiosos, ou seja, como uma disciplina privilegiada para tratar das sexualidades na educação 
escolarizada. Para esse fim, novos estudos, debates e pesquisas sobre a questão são imprescindíveis para a qualificação da formação profissional em Educação Física.

\section{ALGUMAS CONSIDERAÇÕES}

Os modos como vamos construindo nossas representações em relação aos gêneros e às sexualidades estão intimamente ligados às relações sociais que estabelecemos, às instituições e pressupostos que compartilhamos e, também, aos artefatos culturais que intervêm e produzem nossas representações. Nesse contexto, o cinema foi tomado como um potente artefato cultural que ao ser utilizado como uma ferramenta de ensino-aprendizagem possibilitou multiplicar representações e fez circular sentidos e significados enunciados pelos/as acadêmicos/as de Educação Física acerca das relações de gênero e da sexualidade tematizadas nas películas. As representações colhidas nos grupos focais convergem para noções referentes de ser homem ou mulher, ou seja, elas devem ser condizentes com aquilo que se espera de um homem-masculinoheterossexual e uma mulher-feminina-heterossexual.

Na discussão referente ao filme Tomboy (SCIAMMA, 2011), despontam as representações de gênero ligadas às normas referentes do que é entendido como menino-masculino e meninafeminina. Essa conexão foi observada nas manifestações deste grupo específico, a partir da personagem principal Laure, visto que a sua aparência se aproxima tanto de um referente de masculinidade, que convence a ponto de anular a sua designação do sexo feminino. Todavia, a anulação de sua designação sexual feminina acaba por romper com a lógica linear sexo-gênero, descortinando outras possibilidades de arranjos em relação a sexo e a gênero. Outra questãochave levantada nas discussões em relação ao filme está ligada à constituição familiar, centrando nas responsabilidades designadas ao pai e à mãe. Tais representações estão ligadas a uma visão de família, na qual o lugar de um e outro ainda são fixos, ou seja, o lugar da mãe enquanto cuidadora e o pai provedor do lar.

Já na discussão sobre sexualidade baseada em Assunto de Meninas (POOL, 2001), notamos que ao trazer um filme que aborda uma forma não heterossexual de vivenciar a(s) sexualidade(s), o que causa desconforto; entretanto, o desconforto, materializado em silêncios, não parece ser causado única e exclusivamente por se tratar de um filme que aborda uma relação homoafetiva, mas por se tratar de "sexualidades". Em contrapartida, falar a partir do outro se mostrou uma boa estratégia para emergir o que tinham como representação de sexualidade. Além disso, quando o silêncio é quebrado, preconceitos e discriminações acerca das sexualidades não referentes são afirmadas e reafirmadas constantemente, marcando nas incongruências de suas falas e manifestando diferentes condutas em função de a homossexualidade ser vivida por uma pessoa do convívio familiar ou fora desse círculo.

Agregar ao campo da Educação Física discussões que abarquem as relações de gênero e sexualidade ajuda a (re)pensar de que forma determinadas representações sobre relações de gênero e sexualidades acabam reforçando um modelo referente daquilo que se espera de homens e mulheres, a forma como devem vivenciar suas sexualidades, como também de que maneira isso reverbera nas práticas corporais e esportivas. Sendo assim, utilizar o cinema para problematizar essas questões mostrou-se como uma experiência viável e instigante. E mais: sugerimos que outras temáticas sejamtrabalhadas a partir desse artefato cultural na formação profissional em Educação Física, não somente como mais uma possibilidade de estratégia de aula, mas como algo que 
produza outros modos de pensar, desacomodando certezas e abrindo brechas para que a generificação dos corpos e a vivência das sexualidades sejam acolhidas igualitariamente em sua diversidade de manifestações.

\section{REFERÊNCIAS}

1. ALTMANN, H. Orientação Sexual nos Parâmetros Curriculares Nacionais. Estudos Feministas, Florianópolis, ano 9, p. 575-585, 2001.

2. ALTMANN. H. Diversidade sexual e educação: desafios para a formação docente. Sexualidad, Salud y Sociedad - Revista latinoamericana, no 3, p. 69-82, 2013.

3. BARDIN, L. Análise de conteúdo. São Paulo: Edições 70, 2011.

4. BARBOUR, R. Grupos focais. Porto Alegre: Artmed, 2009.

5. BLASCO, P. Medicina da família e cinema: recursos humanísticos na educação médica. São Paulo: Ed. Casa do Psicólogo, 2002.

6. BENTO, B. As tecnologias que fazem os gêneros. In: Anais do VIII Congresso Iberoamericano em Ciência, Tecnologia e Gênero, p. 01-13, 2010.

7. BOGDAN, R; BIKLEN, S. Investigação qualitativa em Educação: fundamentos, métodos e técnicas. In: Investigação qualitativa em educação. Portugal: Porto Editora, p. 15-80, 1994.

8. CARVALHO, M. E. P.; Modos de educação, gênero e relações escola-família. Cadernos de Pesquisa, v. 34, n. 121, p. 41-58, jan./abr, 2004.

9. CEZAR, P. H. N.; GOMES, A. P.; SIQUEIRA-BATISTA, R. O cinema e a educação bioética no curso de graduação em medicina. Revista Brasileira de Educação Médica, 35 (1), p. 93-101, 2011.

10. DAMICO, J. G. S.; Quantas calorias eu preciso [gastar] para emagrecer com saúde? : como mulheres jovens aprendem estratégias para cuidar do corpo. 2004. 161 f. Dissertação (Programa de Pós- graduação em Educação- Universidade Federal do Rio Grande do Sul, Porto Alegre, 2004.

11. DANTAS, A. A.; MARTINS, C. H.; MILITÃO, M. S. R. Cinema como instrumento didático para abordagem de problemas bioéticos: uma reflexão sobre a eutanásia. Revista Brasileira de Educação Médica, n. 35 (1), p. 69-76, 2011.

12. DIAS, C. Esporte e política em Invictus, de Clint Eastwood. Revista Brasileira de Ciências do Esporte. Florianópolis, v. 36, n. 2, p. 515-530, abril/junho, 2014.

13. DINIS, N. F. Educação, cinema e alteridade. Educar, Curitiba: Ed. UFPR, v. 26, p, 67-79, 2005.

14. DUARTE, R. Cinema e educação. Belo Horizonte: Ed. Autêntica; 2002.

15. FABRIS, E. H. Cinema e educação: um caminho metodológico. Educação e realidade, 33(1), p. 117-134, jan/jun, 2008.

16. ELLSWORTH, E. Modos de endereçamento: uma coisa de cinema; uma coisa de educação também. In: SILVA, Tomaz Tadeu da (org.). Nunca fomos humanos. Belo Horizonte: Autêntica, 2001. p.7-76

17. FERREIRA, B. L.; LUZ, N. S. Sexualidade e gênero na escola. In: LUZ, N. S; CARVALHO, M. G; CASAGRANDE L. S. (Org.). Construindo a igualdade na diversidade: gênero e sexualidade na 
escola. Curitiba: UTFPR, 2009.

18. GOELLNER, S. V. Jogos olímpicos e desafios: Carruagens de fogo. In: MELO, V. A.; PERES, F. F. (orgs.). O esporte vai ao cinema. Rio de Janeiro: Editora Senac Nacional, p. 65-73, 2005.

19. GOMES, D. C.; MORAES, A. F. G.; HELAL, D. H. Faces da cultura e do jeitinho brasileiro: uma análise dos filmes auto da compadecida e saneamento básico. Holos, ano 31, v. 6, p. 502-519, 2015.

20. JAEGER, A. A.; GOELLNER, S. V. O músculo estraga a mulher? a produção de feminilidades no fisiculturismo. Estudos Feministas, vol.19, n.3, p. 955-976, 2011.

21. JAEGER, A. A.; Mulheres atletas da potencialização muscular e a construção de arquiteturas corporais no fisiculturismo. 2009. 237 f. Tese (Programa de Pós- graduação em Ciência do Movimento Humano- Universidade Federal do Rio Grande do Sul), Porto Alegre, 2009.

22. JUNQUEIRA, R. D. Introdução - Homofobia nas escolas: Um problema de todos. In: JUNQUEIRA, R. D. (Org.). Diversidade Sexual na Educação: Problematizações sobre a homofobia nas escolas. Brasília: Ministério da Educação/Secretária de Educação Continuada, Alfabetização e Diversidade/UNESCO, p. 13-51, 2009.

23. JUNQUEIRA, R. D. Pedagogia do armário e currículo em ação: heteronormatividade, heterossexismo e homofobia no cotidiano escolar. MILSKOLCI, Richard (Org.). Discursos fora da Ordem: deslocamentos, reinvenções e direitos. São Paulo: Annablume, 2012.

24. KNIJNIK, J.; MELO, V. de A. Football and the 'new' gender order: Brazilian cinema in the late twentieth century. Soccer \& Society, p, 1-16, abril de 2015.

25. LIMA NETO, A. A.; NOBREGA, T. P. Corpo, cinema e educação: cartografias do ver. Holos, ano 30, v, 5, p. 81-97, 2014.

26. LIONÇO, T.; DINIZ, D . Homofobia, silêncio e naturalização: por uma narrativa da diversidade sexual. In: 2009, p. 53) livro homofobia e educação. LIONÇO, T.; DINIZ, D. (Org.) Homofobia \& Educação: um desafio ao silêncio. Brasília: Letras Livres: EdUnB, 2009.

27. LOURO, G. L.; Gênero, sexualidade e educação: uma perspectiva pós-estruturalista. Ed. Vozes, $8^{\circ}$ edição. Petrópolis-RJ, 1997.

28. LOURO, G. L. O Corpo Educado: Pedagogias da Sexualidade. Minas Gerais: Editora autêntica, 2007.

29. LOURO, G. L.; Gênero e sexualidade: pedagogias contemporâneas. Pro-Posições, vol.19, n.2, pp. 17-23, 2008a.

30. LOURO, G. L.; Cinema e Sexualidade. Educação e Realidade. Vol. 33, n. 01, PP. 81-98, 2008b.

31. MELO, V. A. Futebol, cinema e masculinidade: uma análise de Asa Branca, um sonho brasileiro (1981) e Onda Nova (1983). Revista Portuguesa de Ciências do Desporto, v. 9, p. 234-256, 2009.

32. MEYER, D. E. E. Identidades traduzidas: cultura e docência teuto-brasileiro-evangélica no Rio Grande do Sul. Porto Alegre RS: Edunisc \& Sinodal, 2000.

33. PRADO, V. M. do; RIBEIRO, A. I. M. Gêneros, sexualidades e Educação Física escolar: um início de conversa. Motriz, Rio Claro, v. 16, n. 2, p. 402-413, abr./jun. 2010.

34. PINTO, F. M., PEREIRA, L. G. A experiência de ver filmes na formação inicial de professores de 
Educação Física. Revista Pensar a Prática, v.8, n. 1, p. 101-115, 2005.

35. ROSE, G. Visual methodologies - an introduction to the visual interpretation of visual materials. London: Sage Publications, 2001.

36. SILVA, T. T. Documentos de identidade: uma introdução as teorias do currículo. Belo Horizonte: Autêntica, 2002.

37. SILVA, B. O.; RIBEIRO, P. R. C. Sexualidade na sala de aula: tecendo aprendizagens a partir de um artefato pedagógico. Estudos Feministas, vol.19, n.2, p. 521-533, 2011.

38. WALTER, F. O. O lugar do pedagógico nos filmes feitos para crianças. Pro-Posições, v. 26, n. 3 (78), p. 185-204, set/dez, 2015.

39. WEEKS, J. O corpo e a sexualidade. In: LOURO, Guacira (org.). O corpo educado: pedagogias da sexualidade. Belo Horizonte; Autêntica, p. 35-82, 1999.

40. XAVIER, I. Um cinema que "educa" é um cinema que [nos] faz pensar: Entrevista com Ismail Xavier. Educação e Realidade, Porto Alegre, no 33, v. 1, jan/jun, p. 13-20, 2008.

\section{REFERÊNCIAS DOS FILMES}

TOMBOY. Direção de Celine Sciamma, França, 2011.

LOST AND DELIRIUS/ ASSUNTO DE MENINAS. Direção de Leá Pool, Canadá, 2001.

Agradecimento a Capes BEX 1132/14-8. 